\title{
Automated Rating of Financial and Economic Condition of Companies
}

\author{
Aleksandr Mikhaylovich Batkovskiy ${ }^{1}$ \\ Elena Georgievna Semenova² \\ Valerij Yaroslavovich Trofimets ${ }^{3}$ \\ Elena Nikolaevna Trofimets ${ }^{4}$ \\ Alena Vladimirovna Fomina ${ }^{1}$ \\ 1Joint Stock Company "Central Research Institute of Economy, Management and Information Systems "Electronics", \\ Moscow, Russia \\ ${ }^{2}$ The Department of Innovation and Quality Management, St. Petersburg State University of \\ Aerospace Instrumentation, St. Petersburg, Russia \\ ${ }^{3}$ Department of Economic Analysis and Informatics, P.G. Demidov Yaroslavl State University, Yaroslavl, Russian Federation \\ ${ }^{4}$ The Department of Mathematics and Statistics, St. Petersburg Branch of Financial University under \\ Government of Russian Federation, St. Petersburg, Russia \\ Correspondence: Alexander Mikhailovich Batkovskiy, Central Research Institute of Economy, Management Systems and \\ Information Electronics, Cosmonaut Volkov str. 12, Moscow, 127299, Russia. E-mail: batkovskiy_a@instel.ru
}

\section{Doi:10.5901/mjss.2015.v6n5s4p297}

\section{Abstract}

The ratings-based approach to assessment of financial and economic condition of companies was analyzed from the perspective of multiple-criteria selection. The author specifies basic problems to be solved when making integral ratings: selection of the compromise principle and relevant optimality principle; accounting for priorities of the criteria; criteria normalization. The article analyzes one of the most widespread compromise principles of ratings-the principle of fair compromise, which solves the problem of multiple criteria in a radical way through convolution of relevant set of criteria into a single integral criterion. The procedure, which is based on the hierarchical analysis method and some auxiliary computing procedures, which allow to make point and interval assessments of indicators of companies' financial and economic condition, is suggested for hierarchical synthesis of the integral rating. The author considers the procedure application chart, which was brought up to the level of implementation. Automated application was made on the MS Excel tabular processor platform using VBA, and such automated application includes three basic functional subsystems: source data import subsystem; subsystem for assessment of the companies' financial and economic condition; the companies' ratings generation subsystem. The suggested solution may be used as a prototype of a commercial automated system, which allows the customer to specify requirements in respect of the created system, and which allows the developer to adjust its functionality, with direct involvement of system users for this purpose. The developed prototype was tested on the data of six real single-industry companies.

Keywords: companies' rating, multiple-criteria selection, hierarchical analysis method, financial and economic condition, automation

\section{Introduction}

For the purposes of financial regulation of relationships between government customers and producers (suppliers) of goods and services for the government, a competitive-based federal order system is being developed in the Russian economy.

Economic, legal, organizational, technical, special and other relationships between government customers and contractors are built on the basis of public sector contracts. The main methods of contract execution include: open and closed tenders, competitive offers, non-tender procedures, initiative offers from contractors.

The pre-qualification phase is significant in the course of implementation of the tender procedure. Costs do not play a critical role on this phase, while the indicators describing the qualification of the suppliers of products for federal needs are taken into account.

Methodologically, solution of this task requires completion of the following phases:

1) Statement of objective. 
2) Development of the criteria space of the characteristics of assessed items.

3) Receipt of information on relative importance of selected criteria.

4) Development (selection) of the mathematical instrument for comparison of objects and further selection of the most favorable object based on the integral criterion.

5) Performing calculations and interpretation of obtained results.

Formally, the purpose of comparative assessment of suppliers' qualification may be stated as selection of a supplier with the best chances of appropriate fulfillment of the government contract.

Assessment of supplier's financial and economic condition is one of the main components of assessment of the suppliers' qualification. Such assessment results in integral ratings, on the basis of which companies are ranked and the decision regarding further participation in the tender is made.

Speaking of the company's integral rating, we should note that its modern interpretation has the twofold nature. On the one hand, integral rating is thought of as a detailed analysis of all aspects of company's business and financial operations with further preparation of a several dozen page expert opinion with detailed analysis of results. Such approach corresponds (to a greater degree) to the audit report on company's business and financial operations. When applying such approach, it is very hard to compile the results of the analysis into a single integral assessment and to assign the company's rating.

The second approach to integral rating's interpretation does not require deep study of various aspects of company's business and financial operations; its main objective is to obtain an integral rating in a numerical form for further ranking of compared companies. Such approach corresponds to the classic definition of rating as an index number showing importance of a certain object. This approach was used for the suggested procedure of rating of the companies' financial and business condition on the basis of the hierarchical analysis method.

\section{Literature Review}

One of the main problems emerging in the course of companies' rating lies in the rating's reliance on comparison and integration of several heterogeneous indicators. Such circumstance allows to refer the issue of companies' rating to the multi-criteria selection class of problems.

Variety of multi-criteria problems resulted in a huge amount of methods of multi-criteria solution analysisMultiCriteria Decision Analysis, MCDA Yu (1985), Montgolfier and Bertier (1978), Nogin (2002), Larichev (2006), Podinovskiy (2007), Doumpos and Grigoroudis (2013), and others.

On the basis of our analysis, we singled out four consolidated MCDA methods groups and, respectively, four groups of literature sources:

1) Sources focusing on the methods based on quantitative measurements (Winterfeldt \& Edwards, 1986; Keeney \& Raiffa, 1993; Larichev \& Olson, 2001);

2) Sources focusing on the methods based on qualitative measurements, which, however, are transformed into the quantitative form (Zade, 1976; Saaty, 1989; Stain \& Silva, 1994);

3) Sources focusing on methods based on quantitative measurements, but only a few indicators are used for option comparison purposes (Vanderpooten, 1991; Vallee \& Zielniewicz, 1994; Roy, 1996; Zopounidis \& Pardalos, 2010);

4) Sources focusing on the methods which are based on qualitative measurements without any transition to quantitative variables (Larichev, 2006).

Detailed analysis of MCDA methods, particularly with account for various uncertainties, may be found in the following studies Zimmermann (2000), Belton and Stewart (2002), Figueira, Greco and Ehrgott (2005).

Various examples of utilization of multi-criteria analysis methods for solution of financial and economic tasks may be found in the following studies Zopounidis and Pardalos (2010), Xidonas, Mavrotas, Krintas, Psarras and Zopounidis (2012), Saaty and Vargas (2013), Eiselt and Sandblom (2013), Doumpos and Zopounidis (2014), and others.

\section{Methods}

\subsection{General Methodology of Ratings}

The most widespread general methods applied in the companies' ratings include: sum of indicator values, ranking sum, scoring, distance-based method, taxometric method, geometric mean-based method, ratios-based method. 


\subsubsection{Indicator Value Sum-based Method}

This method is applied in case of identical direction of source indicators and their comparability. According to this method, a company with the maximum sum of incentive indicators or the minimum sum of disincentive indicators is considered as the best company:

$$
R_{j}=\sum_{i=1}^{n} a_{i j}
$$

where $R_{j}$ is the rating of $j^{\text {th }}$ company; $a_{i j}$ is a value of $i^{\text {th }}$ indicator of $j^{\text {th }}$ company.

\subsubsection{Ranking Sum-based Method}

Companies are ranked in descending order by incentive indicators and in ascending order by disincentive indicators. Companies are assigned with positions. In case of equal indicator values, companies are assigned with the same positions. Companies with the minimum sum of positions will have the best results under this method:

$$
R_{j}=\sum_{i=1}^{n} M a_{i j}
$$

where $\mathrm{Maij}$ is a position by $i^{\text {th }}$ indicator of $j^{\text {th }}$ company within the group of the same indicators of other companies.

\subsubsection{Scoring}

According to this method, the scales for assessment of each indicator are set in addition to source indicator values. This method requires development of scale-based assessments to be matched against each other:

$$
R_{j}=\sum_{i=1}^{n} B a_{i j}
$$

where Maij is a score of ith indicator of jth company. Ranking sum- and scoring-based methods do not take into account the absolute values of indicators; that's why the assessments obtained using such methods may distort the real picture of achievements of each company, if the companies' variations differ slightly.

\subsubsection{Distance-based Method}

This method takes into account the absolute values of indicators when assessing business performance. The best value (taken as a benchmark) is put into the indicator matrix. Then the distances between the indicators of each company and the reference company ( $m^{\text {th }}$ company) are calculated. Companies are ranked by increase in distance, provided that the lesser the distance, the better the assessment:

$$
R_{j}=\sqrt{\sum_{i=1}^{n}\left(1-\frac{a_{i j}}{a_{i, m}}\right)^{2}}
$$

where $a i, m$ is the value of $i^{\text {th }}$ indicator of $m^{\text {th }}$ reference company.

\subsubsection{The Taxometric Method}

This method takes into account the absolute values of indicators and allows to eliminate their variation; this method resulted from generalization of the distance-based method. The source values matrix is transformed based on the following formulae:

$$
\begin{gathered}
z_{i j}=\frac{a_{i j}-\bar{a}_{i}}{\sigma_{i}} \\
\bar{a}_{i}=\frac{\sum_{j=1}^{m} a_{i j}}{m}
\end{gathered}
$$




$$
\sigma_{i}=\sqrt{\frac{\sum_{j=1}^{m}\left(a_{i j}-\bar{a}_{i}\right)^{2}}{m}}
$$

where $z_{i j}$ is a deviation of $i^{\text {th }}$ indicator of $j^{\text {th }}$ company from the mean value; $a_{i}$ is the mean value of $i^{\text {th }}$ indicator; $\sigma_{i}$ is a standard deviation of $i^{\text {th }}$ indicator; $m$ is the quantity of companies. The reference company is also singled out here, and the minimum sum of deviations from such reference company is considered as the best.

\subsubsection{The Geometrical Mean-based Method}

This method involves calculation of ratios for the assessed indicators, so that $0 \leq k_{i j} \leq 1$. The maximum indicator value is taken as 1. It is reasonable to apply this method in case of a relatively small quantity of assessed indicators and when most their values are close to 1 :

$$
R_{j}=\sqrt[n]{\prod_{i=1}^{n} k_{i j}}
$$

\subsection{The problems of the Multi-criteria Selection in the Course of Ratings}

One of the main problems emerging in the course of companies' rating lies in the rating's reliance on comparison and integration of several heterogeneous indicators. Such circumstance allows to refer the issue of companies' rating to the multi-criteria selection class of problems (Figure 1).

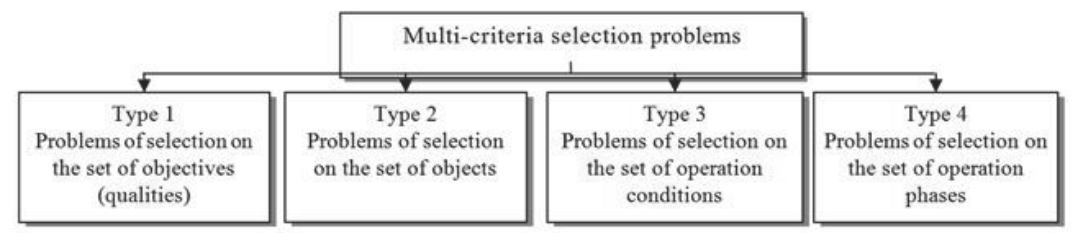

Figure 1. Classification of the multi-criteria selection problems

Problems of this class are common in economic analysis. Typical problems include the issues of economic entities' assessment based on the multilevel set of criteria (type 1 multi-criteria problems) and the problems of planning of allocation of limited funds among financed units on the basis of the priority system (type 2 multi-criteria problems).

Use of several criteria for assessment of economic entities is required for 2 reasons. First if all, many objects of economic analysis possess various characteristics, which cannot be matched against each other, and, hence, they are described with several criteria. Second, it is often difficult to choose out of the assessed criteria one criterion with large degree of preference. In such situation, we need to use a set of criteria, which are considered (on an aggregate basis) as representative criteria. As a result, assessment of analyzed entities based on several criteria cannot be reduced to resolution of a standard mathematical programming problem, since 'the larger (smaller) criterion's value, the better' principle (which is so meaningful when the quantity of criteria $n=1$ ) appears to be insufficient for determination of preference relationships when $n \geq 2$.

Similar problems emerge during planning of money allocation in case of insufficient financing, when a set of criteria (rather than any one criterion) is considered as representative, and each of such criteria describes the degree of financing of relevant entity, .

Basic specific problems to be solved when developing the ways to solve the multi-criteria problems include: selection of the compromise principle and relevant optimality principle; accounting for priorities of the criteria; criteria normalization.

Selection of the compromise principle and relevant optimality principle is the key issue, since it is related to determination of characteristics of an optimal solution and the problem's solution-in what sense optimal solution surpasses the remaining ones. The quantity of possible compromise arrangements is quite large, including the most wellknown uniformity principle (equality principle, max-min principle, quasi-equality principle), fair compromise principle (absolute compromise principle and relative compromise principle), main criterion single-out principle, successive 
compromise principle.

The issue of accounting for the criteria priorities emerges when local criteria have different significance, which results in the need to assess the degree of their influence on problem solving (the need to find the criteria's weights (priorities)).

Normalization problem emerges due to the fact that local criteria have, generally, different units and scales of measurement, which makes direct comparison impossible. Bringing the criteria to the same scale and nondimensionalization are known as normalization. Various criteria normalization methods have been developed.

The above problems have rather conceptual than formal nature, which leads to the need to apply various heuristic procedures, where experts play a significant role. Since expert assessments are subjective, special focus, in our opinion, should be placed on the theoretical relevance of the method and formalized use of heuristic procedures therein when choosing a method of solving the problems of multi-criteria selection.

\subsection{The Reasons for Selection of MCDA Method}

We believe that utility theory methods, fuzzy sets theory methods, vector stratification methods and hierarchical analysis method may be taken from MCDA methods, which, on the one hand, have the acknowledged theoretical relevance, and, on the other hand, may be quite easily adapted and efficiently used for dealing with the issue of rating of companies' financial and economic conditions.

The multi-criteria utility theory suggested by Fishbern allows to obtaining (for multi-criteria selection problems) the multi-attribute utility function, the maximum value of which corresponds to the most favorable option (Fishbern, 1977). The main advantage of the multi-attribute utility methods is the possibility to assess any quantity of options using the obtained function. However, the procedure of utility function construction requires large volumes of information and is quite labor consuming.

Fuzzy sets theory suggested by Zade allows to present knowledge on preferable options by various criteria with the use of fuzzy sets (Zade, 1976). Formation of fuzzy sets is a more simple and less labor consuming procedure as compared with construction of utility functions. The main problem of multi-criteria selection using fuzzy sets lies in presentation of information on relationships between the criteria and integral estimates calculation methods. The methods which are based on different approaches yield different results. Each approach has its own restrictions and peculiarities, and an analyst should get an idea of them before application of a particular decision making method.

Vector stratification methods are based on the procedures of construction of the structured multi-criteria space and its subdivision into the set amount of organized layers (strata) (Glotov \& Pavelev, 1984). Objects belonging to different strata will be organized by the degree of their conformity to the set objective (by significance, priority). Vector stratification methods allow to making a comprehensive assessment and selection of the best considered objects on the basis of both quantitative and qualitative source information.

The hierarchical analysis method suggested by Saaty is a closed logical construction, which allows to analyze diverse serious problems with simple rules (Saaty, 1989). This method is based on paired comparison of options on the basis different criteria. Relationships between the criteria are taken into account by construction of the criteria hierarchy and application of paired comparisons in order to determine the importance of criteria and sub-criteria. Being simple, this method provides good correspondence to intuitive notions. The method has been widely approved for solving weakly structured tasks from various subject fields. The hierarchical presentation of a problem, which is acceptable under the hierarchical analysis method, corresponds (to the fullest extent) to the system of companies' ratings. Besides, it may be easily implemented on the program level within MS Excel tabular processor environment, which is significant for practical use, as it allows to creating small fragments of automated economic solutions support systems by non-programming users without special software. The latter characteristics of the method allow to consider it as one of the basic methods which may serve as the mathematical support of the automated procedure for rating of the companies' financial and economic condition.

The basic algorithm of priorities vectors construction is analyzed (Saaty, 1989) and algorithmic peculiarities of the suggested procedure are analyzed (Batkovskiy, Y. Trofimets, \& N. Trofimets, 2014); so, let's shift our focus to the practical use of the hierarchical analysis method for solution of the problem of rating of the companies' financial and economic condition and development of relevant automated procedure.

\subsection{The Companies' Integral Rating System}

Along with selection of an adequate method of obtaining an integral rating, it is also essential to select a system of 
indicators, on the basis of which such rating will be formed. The indicator system construction process has a certain degree of subjectivity. Methodologies suggested by Kovalev, and Volkova (2002), Schiborsch (2000), Ginzburg (2004), Postyushkov (2001) and INEC LLC (Kotlyar, 1999) use their own indicator systems, with different structures of indicators, their weights or scores. However, similar aspects of the companies' financial and business operations are assessed in the vast majority of methods. That's why we may single out a range of indicators, which are present in all methods and which are important for rating construction purposes.

On the basis of analysis of the indicator system related to the above methods, as well as other indicator systems which are widely described in financial and economic literature, Figure 2 shows the hierarchical integral rating indicator system (Batkovskiy, Y. Trofimets, \& N. Trofimets, 2014).

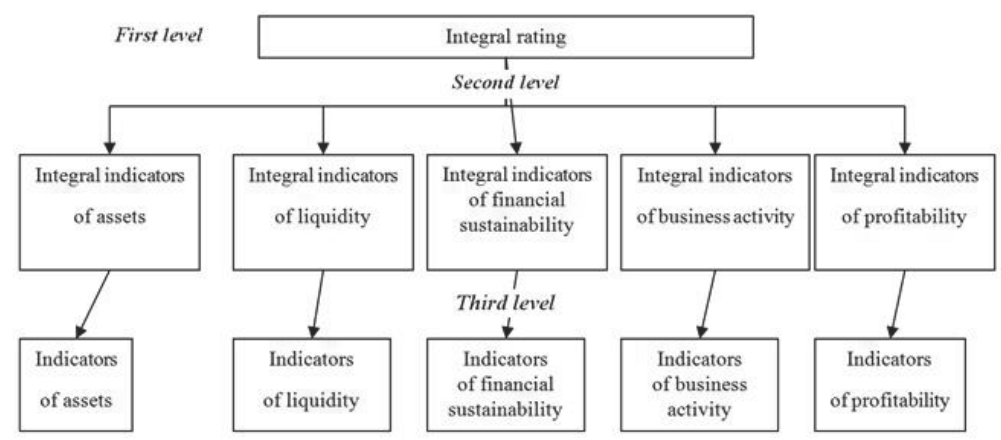

Figure 2. The hierarchical system of companies' integral rating indicators

The suggested indicator system has 3 hierarchy levels. Integral indicators are located on first and second levels. The integral indicator of rating is located on the first level; the second level includes integral indicators of assets, liquidity, financial sustainability, business activity and profitability. The third level of the hierarchy includes five groups of indicators, the values of which are calculated on the basis of financial statements (Table 1).

Table 1. Indicators of the third level of hierarchy

\begin{tabular}{ll}
\hline Group & Indicators \\
\hline \multirow{3}{*}{ Asset indicators } & Percentage of fixed assets in use; \\
& Fixed assets wear coefficient; \\
& Renewal ratio; \\
& Retirement ratio. \\
\hline & Working capital; \\
& Flexibility of working capital; \\
& General coverage ratio; \\
& Instant liquidity ratio; \\
& Absolute liquidity ratio; \\
& Working capital to assets ratio; \\
& Inventory to working capital ratio; \\
Liquidity indicators & Inventory to working capital ratio; \\
& Inventory coverage ratio. \\
& Equity capital concentration ratio; \\
& Leverage; \\
& Equity flexibility ratio; \\
& Debt concentration ratio; \\
& Long-term investment structure ratio; \\
& Long-term debt ratio; \\
& Debt structure ratio; \\
Financial sustainability indicators & Debt to equity ratio. \\
\hline Business activity indicators & Labor productivity; \\
& Return on assets; \\
\hline
\end{tabular}




\begin{tabular}{ll}
\hline & Accounts receivable turnover ratio; \\
Inventory turnover ratio; & Accounts payable turnover ratio; \\
& Operating cycle; \\
& Financial cycle; \\
& Equity turnover ratio; \\
& Fixed asset turnover ratio; \\
& Economic growth sustainability ratio \\
\hline & Product profitability; \\
& Profitability of core operations; \\
& Return on fixed assets; \\
Profitability indicators & Return on equity; \\
& Equity payback period. \\
\hline
\end{tabular}

We should mention that, first of all, the suggested indicator system describes (in sufficient detail) various aspects of the companies' business and financial operations, and, second, it may be processed in an efficient manner using the hierarchical analysis method.

Adequate placement of indicator weights represents the second essential aspect of the issue. Indicator weights may be obtained by finding the vectors of priorities, which are the result of processing of paired comparison matrices. Analysts are required for construction of paired comparison matrices. On the one hand, this contributes a certain share of subjectivity to the suggested method, and, on the other hand, makes the method more adaptive and allows to adjust weights to specific character of compared companies.

The third important aspect of the issue under consideration is represented by processing of third hierarchical level indicator values in order to obtain the initial vectors of priorities, from which the integral rating's hierarchical synthesis begins. As mentioned above, the third level of hierarchy includes indicators, the numerical values of which are calculated on the basis of financial statements. In such case, absolute indicator values should be transformed into relative values, which could be used in hierarchical synthesis of integral rating.

Relative values (priorities vectors) may be obtained on the basis of the typical procedure of pairwise comparison of companies based on comparable indicators. At the same time, the numerical nature of considered indicators allows to use other, more objective methods of obtaining priorities vectors without engagement of experts (Batkovskiy, Y. Trofimets, \& N. Trofimets, 2014).

Therefore, the basis of the developed procedure is represented by the suggested hierarchical system of the companies' ratings, the hierarchical analysis method, as well as the set of developed calculation procedures for construction of initial the vectors of the companies' priorities. 


\subsection{Procedure Chart.}

Figure 3 shows the chart describing application of the developed procedure.

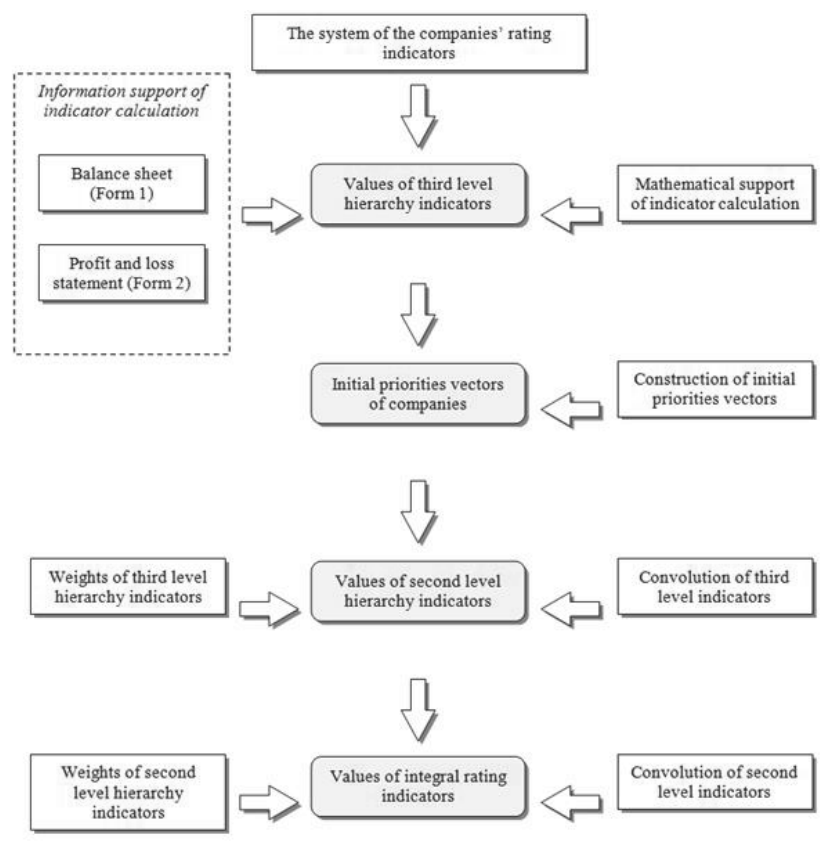

Figure 3. Application of the procedure for rating of the companies' financial and economic condition on the basis of hierarchical analysis

The hierarchic synthesis of the integral rating indicator in the above procedure is based on the fair compromise principle, which solves the problem of multiple criteria in a radical way through convolution of relevant set of criteria into a single integral criterion. In turn, this principle includes the absolute fair compromise principle and the relative fair compromise principle.

The absolute compromise principle corresponds to the optimality principle providing for maximization of the sum of products of local criteria by their weights:

$$
Q=\sum_{i=1}^{k} w_{i} q_{i}
$$

Under this compromise principle, high values of the integral criterion are derived from high values of certain local criteria and relatively low values of other criteria, i.e. there is sharp differentiation of levels of some local criteria.

The relative compromise principle corresponds to the optimality principle providing for maximization of the products of criteria raised to the power of their weights:

$$
Q=\prod_{i=1}^{k} q_{i}^{w_{i}}
$$

The relative compromise principle is quite sensitive to the values of local criteria; due to relativity of compromise, the 'price' of compromise automatically decreases for local criteria with high values, and vice versa. This results in significant smoothing of local criteria levels.

The analyzed integral criteria (additive and multiplicative) lead to the solutions which are the extreme special cases of the solution region, set by the generalized aggregation operator:

$$
Q=\sum_{i=1}^{k} w_{i} q_{i}^{1 / p}
$$


where $p$ is the coefficient setting the type of the aggregation operator.

When $p=1$, the operator becomes additive; when $p<1$, the operator becomes quasi-disjunctive; when $p>1$, the operator becomes quasi-conjunctive. When $p \rightarrow \infty$, the solution set by the generalized aggregation operator asymptotically verges towards the solution set by the multiplicative operator.

The sense of the quasi-conjunctive operator lies in the fact that with small values of one or several aggregated criteria the operator's value decreases disproportionally to $x$. Application of quasi-conjunctive operators (as well as the multiplicative operator) is determined by the following rule: all aggregated criteria should have high values so that the value of the integral criterion (aggregated operator) remains high.

The following rule is a condition for using quasi-disjunctive (and additive) operators: at least one (or several) aggregated criterion (criteria) should have high value (-s), so that the value (-s) of the integral criterion (aggregated operator) remains high. We should note that quasi-disjunctive operators are much less sensitive to change in $p(0<p<1)$, as compared with quasi-conjunctive operators $(p>1)$, so the former ones may be excluded from consideration in the course of practical solution of the tasks.

As for the analyzed procedure, the hierarchic synthesis of the integral rating indicator corresponds mostly to relative fair compromise principle, i.e. the quasi-conjunctive operator.

\section{Results}

Efficient implementation of the developed procedure in the competitive qualification-based selection of suppliers of products for federal needs is possible only if it is realized on the program level. That's why we suggested the prototype of the automated rating system for the companies' financial and economic condition. The prototype is thought of as an operating model of the prospective automated system, which allows the customer to specify requirements in respect of the created system, and which allows the developer to adjust its functionality, with direct involvement of system users for this purpose.

In order to develop the prototype quickly, we used MS Excel tabular processor, which is a universal platform for development of small-scale information systems rather than just an office software. The suggested prototype includes three basic functional subsystems: source data import subsystem, the subsystem for calculation of the companies' financial and economic condition indicators and the companies rating generation subsystem (Figure 4).

On the first phase of system's operation, the quantity of compared companies is specified, on the basis of which the system's configuration is made-generation of required templates for import of output data and calculation of financial indicators of comparable companies. The tender arrangers send to the participating companies e-mails, blank forms (files) of financial statements in MS Excel tabular processor format. After the forms are filled out, they are returned to the tender arrangers. Sent files with filled-in data are transferred for processing to source data import subsystem, where they are checked for accuracy. After the data are checked for accuracy, they are transferred to the subsystem for calculation of the companies' financial and economic condition indicators (Figure 5).

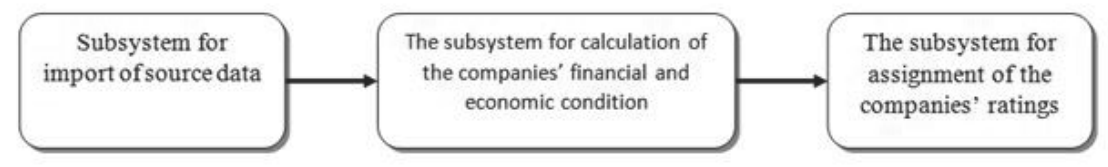

Figure 4. The functional and structural model of the automated system of rating of the companies' financial and economic condition 


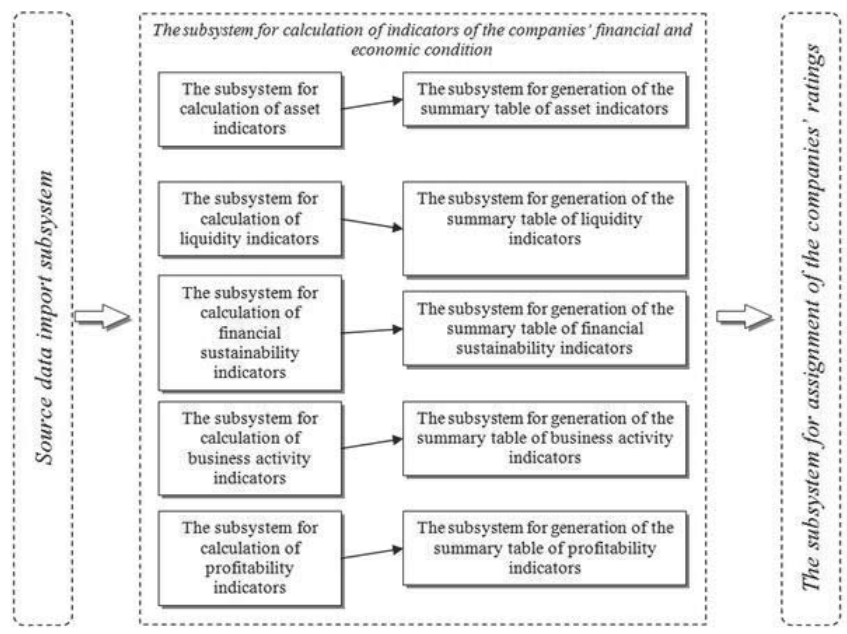

Figure 5. The functional and structural model of the subsystem for calculation of the companies' financial and economic condition

The subsystem for calculation of the companies' financial and economic condition is described on 'Indicators' and 'Summary Tables' sheets with the use of MS Excel standard tools, as well as with the use of the procedures developed by us in VBA language for making summary tables with indicators. The summary tables include the estimated indicators of the companies' financial and economic condition, specified in Table 1. The estimated indicators are transferred to the subsystem for assignment of the companies' ratings (Figure 6).

The subsystem for assignment of the companies' ratings is described on 'Initial Priorities Vectors' and 'Ratings' sheets using standard MS Excel tools.

The developed prototype was tested on the financial statements' data of six real companies. Table 2 shows the estimated values of companies' integral ratings (Batkovskiy, Y. Trofimets, \& N. Trofimets, 2014).

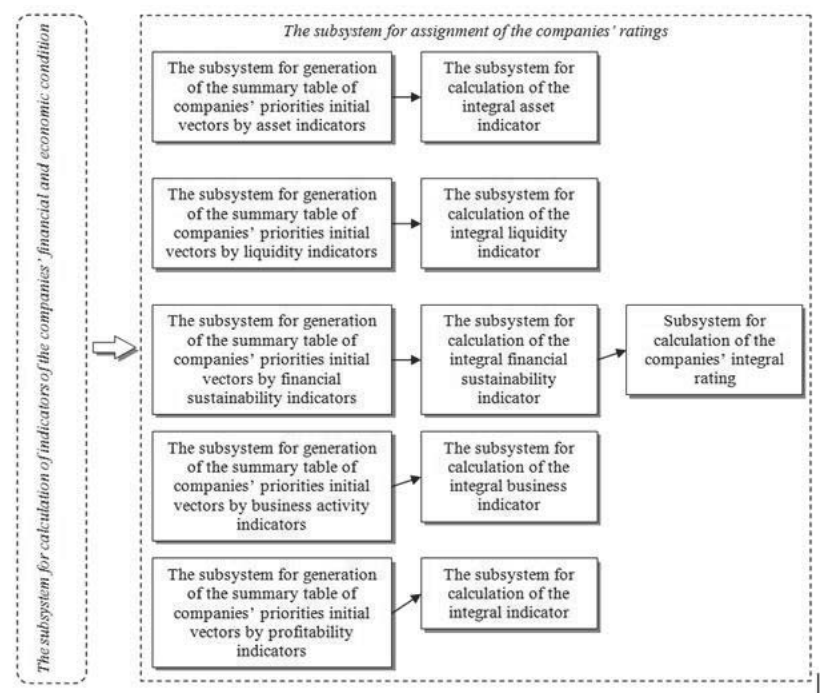

Figure 6. Functional and structural model of the subsystem for assignment of the companies' ratings 
Table 2. Values of the companies' integral ratings

\begin{tabular}{cc}
\hline Company & Value \\
\hline Rubin & 0.10 \\
Sigma & 0.11 \\
Orion & 0.25 \\
Delta & 0.18 \\
Alfa & 0.09 \\
Foton & 0.26 \\
\hline
\end{tabular}

The final ranking of companies is shown in Table 3.

Table 3. Final ranking of companies

\begin{tabular}{ccc}
\hline Company & Rank & Place \\
\hline Foton & $1^{\text {st }}$ & $1^{\text {st }}$ \\
Orion & $2^{\text {nd }}$ & $2^{\text {nd }}$ \\
Delta & $3^{\text {rd }}$ & $3^{\text {rd }}$ \\
Sigma & $4^{\text {th }}$ & $4^{\text {th }}$ \\
Rubin & $5^{\text {th }}$ & $5^{\text {th }}$ \\
Alfa & $6^{\text {th }}$ & $6^{\text {th }}$ \\
\hline
\end{tabular}

\section{Discussion}

Most phases are formalized and strictly substantiated in the developed procedure, which allows to significantly reducing the subjectivity, which is intrinsic to all methods with the elements of expert judgments. Uncertainty is present within the developed procedure only when indicator weights are set for the second-level hierarchy, for which analysts should be engaged. If collective expert examination with open discussion is held, it will result in collectively elaborated judgments regarding the degrees of preference in respect of $i$ indicators as compared with $j$ indicators on the hierarchical analysis method's scale. Elaborated collective judgments are processed under the typical procedure of the hierarchical analysis method, which is equivalent to processing of judgments from one expert.

If experts make their judgments on preferences independently, then judgments may be aggregated by different means, depending on the aggregation phase. When expert judgments are aggregated prior to beginning of processing thereof with the use of the developed procedure, it would be logical to use the geometric mean formula:

$$
a_{i j}^{A}=\sqrt[n]{a_{i j}^{1} \times a_{i j}^{2} \times \ldots \times a_{i j}^{n}}
$$

The logic behind formula (9) becomes obvious, if two equally important analysts point out (when comparing indicators of, respectively, assessment $a_{i j}$ and $\frac{1}{a_{i j}}$, that the estimated aggregated assessment yields 1 and evidences equivalence of the compared indicators. Aggregated judgments $a_{i j}^{A}$ are processed based on the typical hierarchical analysis method.

Then, after obtaining reasonable sustainable assessments $a_{i j}^{A}$, and, therefore, weights of hierarchy's second- and third-level indicators, there will not be any need in analysts, which significantly facilitates the procedure of obtaining of ratings and essentially decreases the subjectivity intrinsic to such methods.

Meanwhile, despite all advantages of the developed rating procedure for the companies' financial and economic condition, we should note that it stipulates utilization of aggregated expert assessments $a_{i j}^{A}$, obtained during the preliminary discussion phase. In addition to this situation, other situations may also happen in practice when tender conditions require to aggregate expert judgments on the final phase. In such case the simplest approach would be to find the arithmetic mean (or median) of priorities vectors' components. Besides, if another expert examination is possible, only the coefficient of concordance may be calculated in advance. If such ratio is, for example, less than 0.5 , then judgments will be deemed inconsistent, and discussion of examination results will be held, following which new judgments will be made. If the coefficient of concordance is at least 0.5 , the arithmetic mean (or median) of the priorities vectors components will be found. 


\section{Conclusion}

There are various methodological approaches to obtaining the company's integral rating: Sum of indicator values, ranking sum, scoring, distance-based method, taxometric method, geometric mean-based method etc. There are other methods of companies' rating in addition to the general methodological approaches, e.g. the methodologies developed by Kovalev and Volkova (2002), Schiborsch (2000), Ginzburg (2004), Postyushkov (2001) and INEC LLC (Kotlyar, 1999), etc. Each of the above methods includes its own set of indicators of financial and economic condition of an entity, allocation of weights and the procedure of convolution into an integral indicator, which results in various ratings. All components of the above methods are also inherent to the suggested automated procedure of rating of companies' financial and economic condition. That's why tender arrangers face the problem of selecting a single method, based on which they will rate companies, or the problem of selecting several reputable methods. We believe that the latter approach is more reliable, but in this case a collective rating need to be made by way of aggregation of several rankings obtained using each method. Such aggregation can be made on the basis of the Kemeny's median or using simpler methods based on generally accepted position indicators (mean, median, quartiles).

\section{Acknowledgements}

This research project was supported by the Russian Scientific Fund (RSF Project No. 14-18-00519).

\section{References}

Batkovskiy, A. M., Trofimets, V. Y., \& Trofimets, E. N. (2014). Rating tools to assess the economic status of enterprises. Economic analysis theory and practice, 36, 2-12.

Belton, V., \& Stewart, T. (2002). Multiple Criteria Decision Analysis: An Integrated Approach. Dordrecht: Kluwer Academic Publishers. Doumpos, M., \& Grigoroudis, E. (2013). Multicriteria Decision Aid and Artificial Intelligence: Links, Theory and Applications. Wiley.

Doumpos, M., \& Zopounidis, C. (2014). Multicriteria Analysis in Finance. Springer.

Eiselt, H. A., \& Sandblom, C. L. (2013). Operations Research: A Model-Based Approach. Springer.

Figueira, J., Greco, S., \& Ehrgott, M. (2005). Multiple criteria decision analysis: State of the art surveys. New York: Springer Science. Business Media, Inc.

Fishbern, P. (1977). Utility theory for decision making. Moscow: Nauka.

Ginzburg, A. I. (2004). Economic analysis. Sankt-Peterburg: Piter.

Glotov, V. A., \& Pavelev, V. V. (1984). Stock stratification. Moscow: Nauka.

Keeney, R. L., \& Raiffa, H. (1976). Decisions with multiple objectives: Preferences and Value tradeoffs. New York: Wiley.

Kotlyar, E. V. (1999). Comprehensive assessment of the financial and economic state enterprises. Ryinok tsennyih bumag-Securities market, 16, 39-41.

Kovalev, V. V., \& Volkova, O. N. (2002). Analysis of economic activity of the enterprise. Moscow: TK Velbi.

Larichev, O. I. (2006). Verbal Decision Analysis. Moscow: Nauka.

Larichev, O. I., \& Olson, D. L. (2001). Mulbiple Criteria Analysis in Strategic Silting Problems. Boston: Kluwer Academmic Publishers.

Montgolfier, J., \& Bertier, P. (1978). Approche Multicritere des Problems de Decision. Paris: Edicions Hommes et Techniques.

Nogin, V. D. (2002). PDecision-making in multicriteria environment: A quantitative approach. Moscow: Fizmatlit.

Podinovskiy, V. V. (2007). Introduction to the importance of criteria in multicriteria decision problems. Moscow: Fizmatlit.

Postyushkov, A. V. (2001).Competitiveness Ranking. Risk, 4, 64-71.

Roy, B. (1996). Multicriteria methodology for decision aiding. Dordrecht: Kluwer Academic Pulisher.

Saaty, T. L. (1989). Making decisions. The analytic hierarchy process. Moscow: Radio i svyaz.

Saaty, T. L., \& Vargas, L. G. (2013). Decision Making with the Analytic Network Process: Economic, Political, Social and Technological Applications with Benefits, Opportunities, Costs and Risks. Springer.

Schiborsch, K. V. (2000). Comparative analysis of competitiveness and financial condition of the industry and / or region. Marketing in Russia and abroad, 5, 92-111.

Stain, A., \& Silva, A. P. (1994). Stochastic judgements in the AHP: The measurement of rank reversal probabilities. Laxenburg.

Vanderpooten, D. (1991). The construction of prescriptions in ontranking methods. In C. B. Costa (Ed.), Readings in Multiple Criteria Decision Aid. Berlin: Springer Verlag.

Winterfeldt, D., \& Edwards, W. (1986). Decision Analysis and Behavioral Research. Cambridge University Press.

Xidonas, P., Mavrotas, G., Krintas, T., Psarras, J., \& Zopounidis, C. (2012). Multicriteria portfolio management. Springer.

Yu, P. L. (1985). Multiple-criteria decision making: Concepts, techniques, and extensions. New York: Plenum Press.

Zade, L. (1976). The concept of linguistic variable and its application to the approximation of solutions. Moscow: Mir.

Zopounidis, C., \& Pardalos, P. M. (2010). Handbook of Multicriteria Analysis. Springer.

Zimmermann, H. (2000). An application-oriented view of modeling uncertainty. European Journal of Operational Research, 122, 190198. 